\title{
Use of Private and Public Health Facilities for essential Maternal and Child Health Services in Nairobi City informal settlements: Perspectives of Women and Community Health Volunteers
}

\author{
Pauline Bakibinga $^{\mathrm{a}}$, Abdhalah K Ziraba ${ }^{\mathrm{a}}$, Remare Ettarh ${ }^{\mathrm{b}}$, Eva Kamande ${ }^{\mathrm{a}}$, Thaddaeus Egondi ${ }^{\mathrm{c}}$, \\ and Catherine Kyobutungi ${ }^{\mathrm{a}}$ \\ ${ }^{a}$ Health Challenges and Systems Research Program, African Population \& Health Research Center, Manga \\ Close, Off Kirawa Road, P.O. Box 10787-00100, Nairobi, Kenya \\ ${ }^{\mathrm{b}}$ Alberta Innovates - Health Solutions, Edmonton, Alberta, Canada \\ ${ }^{\mathrm{c}}$ Independent consultant \\ paulabak80@gmail.com
}

\begin{abstract}
We describe the sources of care for delivery, family planning and child welfare services in urban slums of Nairobi. We further explore the perceptions of women and community health volunteers regarding choice and quality of services at health facilities. Data are from a cross-sectional study conducted in 2013 involving interviews with 849 women aged 12-49 years, 968 caregivers of children under five years, and focus group discussions with a subset of the women and community health volunteers. The findings showed that most women sought delivery care and family planning services from private health facilities (51.5\% and $47.4 \%$, respectively). Private health facilities were preferred because of ease of access and quality of care although their service fees were considered high. By contrast, public health facilities were viewed as affordable and staffed by qualified personnel although they were characterised by long queues and poor provider attitudes.
\end{abstract}

Keywords: Public, Private, Maternal and Child Health, Slums, Kenya

\section{Résumé}

Nous décrivons les sources de soins pour l'accouchement, la planification familiale et les soins de l'enfant dans les bidonvilles urbains de Nairobi. En plus, nous explorons les perceptions des femmes et des volontaires de santé communautaire concernant le choix et la qualité des services dans les établissements de santé. Les données sont tirées d'une étude transversale menée en 2013 à partir d'interviews avec 849 femmes âgées de 12-49 ans, 968 parents ou adultes ayant en charge des enfants de moins de cinq ans, et des groupes de discussion avec un sous-ensemble des femmes et des volontaires de santé communautaire. Les résultats ont montré que la plupart des femmes ont obtenu des soins pour l'accouchement et la planification familiale à partir des établissements de santé privés (5I,5\% et $47,4 \%$, respectivement). Les établissements de santé privés ont été préférés en raison de la facilité d'accès et de la qualité des soins, bien que leurs coûts soient plus élevés. En revanche, les établissements de santé publics considérés comme abordables et dotés d'un personnel qualifié, bien qu'ils soient aussi caractérisés par de longues files d'attente et des comportements déplorables des prestataires de soins.

\section{Introduction}

Whereas the role of the private sector in delivering health care has grown worldwide, its importance is marked in developing countries, particularly in Africa where it covers health care needs of over $50 \%$ of the population (I). The growth of the sector in subSaharan Africa has led to debates about how it compares with and complements the public sector. Studies on health care provision in Africa still paint a mixed picture regarding the utilization of public and private health care sectors. The World Health Organization's multi-country study report on the health systems in Africa reveals that health care is mostly sought from the public sector despite the fact that users viewed these services as inadequate (2). A review conducted by Basu and colleagues found that in many developing countries, removal of unlicensed providers encourages more people to seek services from the public sectors (3). However, other reports show that the private sector is largest provider of health care in developing countries, particularly among the poor (5-7). The private sector is increasingly regarded as part of the "continuum of 
care" with the potential to contribute to increased health service uptake among the poor (8). In addition, debates still abound as to which of the two sectors is more efficient in delivering health services $(3,9)$.

Across sub-Saharan Africa, the private sector, in comparison to the public sector, is appreciated for ease of access, quality services, great responsiveness to clients' needs, and flexible payment structures (3, I0-I4). However, many private providers in underserved settings offer services of questionable quality and of limited variety (I5). The public sector, on the other hand, is perceived to offer a wide variety of services that are affordable and of good quality due to availability of qualified personnel and close regulation of the sector $(3,16-18)$. Yet there are reports of inconclusive evidence on the differences between the sectors in terms of health outcomes, especially for the poor $(9,19)$, reflecting the need for carefully designed interventions that can be evaluated to inform policy and practice regarding the role of public-private partnerships.

In Kenya, slums and slum-like settlements are home to about $60 \%$ of urban residents (20). This is due to rapid urbanization in the country with a rate of urban growth of $4 \%$ per annum compared to the annual population growth rate of $2.9 \%$ (2I). Unfortunately the expansion of public health service delivery system has not matched the urban population growth. Prompt access to quality health care and timely referrals, especially for pregnant women and children are critical for reducing avoidable mortality. Research conducted in urban slums of Kenya reveals that public health facilities are either non- existent or inaccessible in these settings (7). The absence and/or dismal quality of health services has partly contributed to the urban poor having poorer health indicators than other urban and rural residents $(22,23)$. Health care delivery in this setting is largely the domain of a thriving but largely unregulated private health sector which has grown to fill the gap in service delivery. More women in the slums give birth in private health facilities than in government ones (8). However, the range and quality of services in these facilities are questionable.

A study conducted in 2008 using verbal autopsies showed that maternal mortality in slums is high at $706 / 100000$ compared to the national estimate; $488 / 100000$ in $2008 / 9$ and $4 / 4 / 100000$ in 2003 (23). Although institutional delivery is estimated at about $70 \%$, only $40 \%$ of deliveries occurred in an appropriate facility with ability to handle basic obstetric and child complications (24). Even though most slums are within $10 \mathrm{~km}$ of major health care facilities in the city, many women still deliver at home with help of traditional birth attendants or relatives (25). Despite the dismal quality of health services in private health facilities in the slums, studies show that women who seek care from these outlets usually report satisfaction with the services in terms of ease of access and quality of care as opposed to public health facilities that are viewed as inaccessible and unfriendly $(8,14)$.

The existing studies are largely based on quantitative assessments, focus on perceived quality of services in health services, and lack qualitative information that might provide explanations for the reported perceptions about quality of care. This paper uses a mixed methods approach to examine the perspectives of women and community health volunteers (CHVs) regarding use and quality of maternal and child health services in public and private health facilities in Nairobi's informal settlements. It specifically examines the sources of care for selected maternal and child health $(\mathrm{MCH})$ services (family planning, delivery and treatment of childhood illnesses) as well as the perceptions of women and community health volunteers regarding the choice of particular providers and the quality of care received from such providers.

\section{Data and Methods \\ Design and Setting}

This paper uses baseline data from an on-going intervention project titled 'Partnership on Maternal, Newborn and Child Health' (PAMANECH). The project is being implemented in Korogocho and Viwandani informal settlements of Nairobi, Kenya. The broader aim of the project is to strengthen the health care delivery system in the urban informal settlements to be more responsive to the health needs of mothers and their children through enhanced public-private partnerships. The ultimate goal of the PAMANECH project is to improve health service delivery in the private sector and harness the synergies of both public and private sectors to offer better health services for better maternal, newborn and child health outcomes. This goal is to be met through several activities including; infrastructural upgrade of selected Private Not-For-Profit (PNFP) health facilities operating in the two slums, building capacity for both health care providers and the sub County Health Management Teams in Ruaraka, Kasarani and Makadara sub-counties of Nairobi, where Korogocho and Viwandani slums, respectively are located, facilitating provision of supportive supervision by the local district health authorities and forming networks of $\mathrm{CHVs}$ to create demand for the health services.

The baseline survey uses a mixed methods approach and was designed and implemented to provide information on key program elements for subsequent monitoring and evaluation of the project's 
performance. Data collection took place between June and August 2013 and involved a household survey and focus group discussions (FGDs) with residents of the two slums. The African Population and Health Research Center (APHRC) has been implementing the Nairobi Urban Health and Demographic Surveillance System (NUHDSS) in Korogocho and Viwandani since 2002. The NUHDSS provided the sampling frame for the study. As part of the baseline assessment, women of reproductive age were asked to identify their sources of health services (public or private), their preferences regarding public and private health care providers, and their perceptions about the quality of services.

\section{The household survey and sampling procedure}

Two survey tools were used to capture quantitative information: a woman's questionnaire for women of reproductive age and a child's questionnaire for caregivers of children under five years of age. The woman's questionnaire was administered to 849 women aged 12-49 years while the child's questionnaire was administered to 968 caregivers from 936 households. Both groups of participants were randomly selected from the most up-to-date NUHDSS database. The sampling was restricted to those households that had both a woman of reproductive age and a caregiver of a child below five years of age. A system of random numbers generated using STATA was used to separately select the two groups of participants. Information was captured through face-to-face interviews by trained field workers. Participants provided information on background characteristics (such as age, education level, marital status, and source of income) and health-seeking behaviour. The questionnaires were drafted in English and translated into Kiswahili. All interviews were conducted in Kiswahili.

Quantitative data were captured using net books and synchronized with the master database at APHRC head office on a daily basis. The office editor carried out consistency checks and in cases of missing data or inconsistent entries, $s /$ he informed the data manager who then contacted the field teams (team leader) for clarifications. Where need arose, queries were sent back to the field teams for correction. Clean data were exported into STATA for analysis.
Analysis of quantitative data involved obtaining frequencies and percentages for different categories. The outcomes considered were sources of care for child treatment, family planning and delivery services as well as perceptions about quality of care for child treatment. Perceptions about quality of care were categorized as either good (combining 'good' or 'very good') or poor (combining 'poor' or 'average'). Analysis was stratified by type of sector (public, private, and public/private for individuals who sought care from both sources) and slum settlement.

\section{Qualitative interviews}

Participants in the focus group discussions were purposively identified from among those that participated in the household survey based on reported use of specific $\mathrm{MCH}$ services. Separate FGDs were conducted with younger (I 2-24 years) and older (25-49 years) women and for those with and without children. A total of 8 FGDs were conducted: 4 with women with children and another 4 with women without children stratified by age (1224 and 25-49 years). In addition, 2 FGDs were conducted with $\mathrm{CHVs}$, one in each slum. The purpose of the FGDs was to capture information that would not only explain some of the patterns in the quantitative data but also provide insights on perceptions about sources of $\mathrm{MCH}$ services in the community.

The FGDs were conducted in Kiswahili and audiorecorded. A guide that was pre-tested and modified ahead of data collection was used to steer the discussions. Each FGD was moderated by a trained field interviewer who was supported by another field worker taking notes. On average, the FGDs lasted 50 minutes. The discussions were later transcribed and translated into English by an experienced transcriber. The discussion notes were supplemented by observational notes of each FGD. Data were analysed using a thematic approach that entailed initial reading and re-reading of the transcripts while listening to the audio recordings (26). A preliminary coding scheme was then developed based on themes used when designing the discussion guide in order to describe and interpret the women's experiences. The codes were then grouped under key themes. The analysis focused on main areas of consensus and disagreement.

\section{Analysis}


Table I: Group Composition and Discussion Guide for the Focus Group Discussions

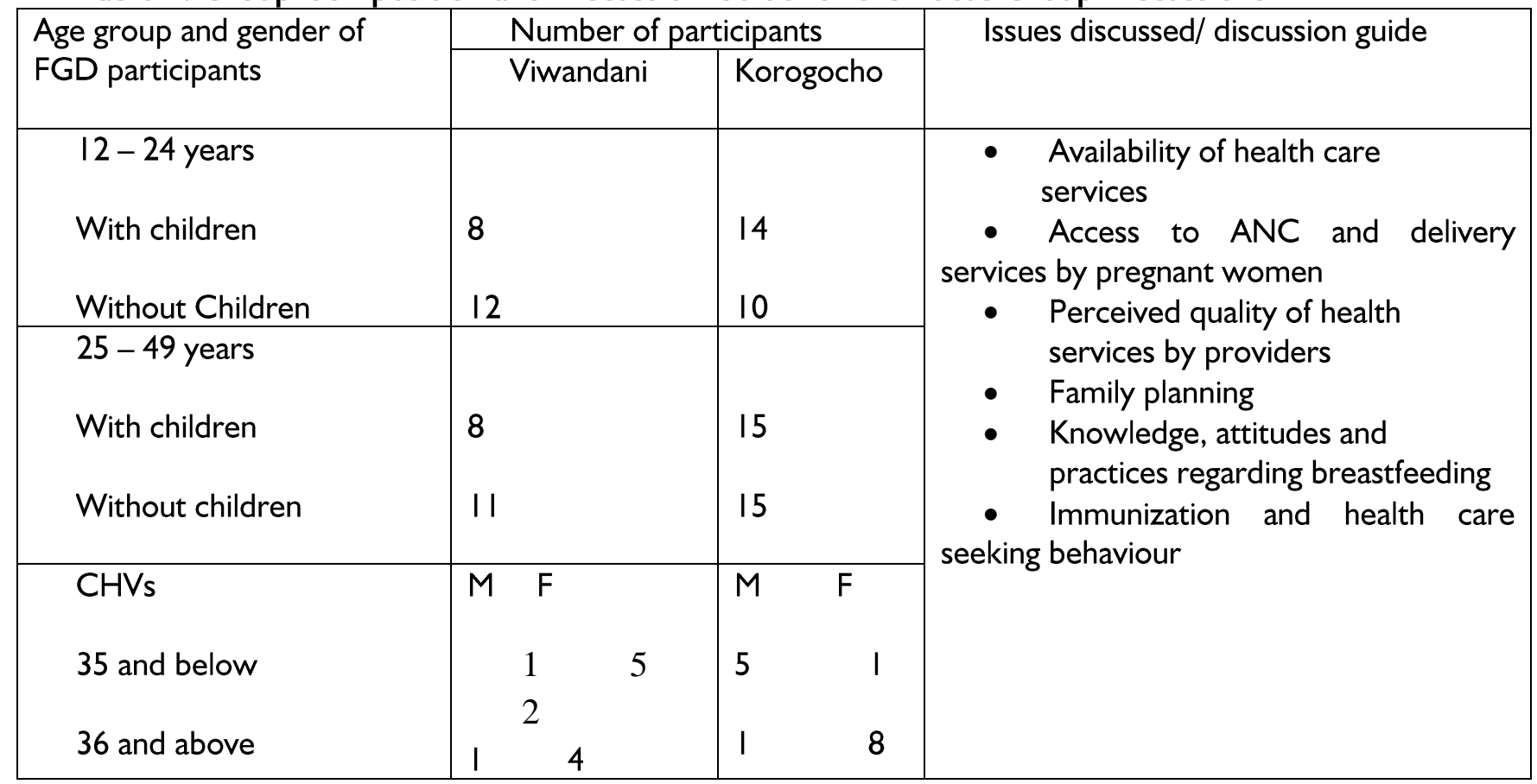

Source: PAMANECH Baseline Household Survey August - October 2013

\section{Ethical considerations}

The study obtained ethical approval from APHRC Institutional Review Board and the Kenya Medical Research Institute (KEMRI) Ethics Review Committee (authorization reference KEMRI/ KEMRI- NONSSCPROTOCOL No. 393).

The research team first visited the households sampled for each data collection activity to inform them about the study, deliver a letter of invitation, and make an appointment to conduct the survey when necessary. Village elders and staff of the subcounty Health Management Teams were also informed. Before the start of all interviews, an information sheet was read to the participants explaining the purpose of the research, the institutions involved, and the nature of their requested participation. Participants were given the opportunity to ask questions. It was emphasised that the information collected would be confidential and that no individual details would be shared with third parties. Written consent was obtained from all interviewees or, where one could not sig thumbprint was taken. Consent was also sought specifically for the use of tape recorders during FGDs.

\section{Results}

Table 2 presents the distribution of survey respondents by background characteristics and study site. Forty percent of the respondents were aged between 21 and 30 years $(34 \%$ and $46 \%$ in Korogocoho and Viwandani, respectively). The proportion of women aged below 20 years was higher in Korogocho than in Viwandani $(33 \%$ and $18 \%$ respectively). The proportion with at least secondary level education was, however, higher in Viwandani than Korogocho $(49 \%$ and $27 \%$ respectively). Similarly, the proportion of women whose spouses had at least secondary level education was higher in Viwandani than in Korogocho $(62 \%$ and $41 \%$ respectively). About half $(51 \%)$ of the women were married at the time of the survey $(46 \%$ in Korogocho and $57 \%$ in Viwandani). Nine percent of the women did not know the level of education of their spouses. 
Table 2: Background characteristics of survey respondents by study site (slum settlement)

\begin{tabular}{|c|c|c|c|}
\hline & $\begin{array}{l}\text { Korogocho } \\
(n=440)\end{array}$ & $\begin{array}{l}\text { Viwandani } \\
(\mathrm{n}=409)\end{array}$ & $\begin{array}{l}\text { Total } \\
(\mathrm{n}=849)\end{array}$ \\
\hline & $\mathrm{n}(\%)$ & $\mathrm{n}(\%)$ & $\mathrm{n}(\%)$ \\
\hline \multicolumn{4}{|l|}{ The age of respondent } \\
\hline$<21$ yrs & $145(33.0)$ & $75(18.3)$ & $220(25.9)$ \\
\hline $21-30$ yrs & I5I (34.3) & $188(46.0)$ & $339(39.9)$ \\
\hline $31-40$ yrs & $105(23.9)$ & $108(26.4)$ & $213(25.1)$ \\
\hline $40+y r s$ & $39 \quad(8.9)$ & $38(9.3)$ & $77(9.1)$ \\
\hline \multicolumn{4}{|l|}{ Current marital status } \\
\hline Married & $203(46.2)$ & $23 \mid(56.6)$ & $434(5 \mid .2)$ \\
\hline Separated/divorced/widowed & $49(|| .2)$ & $61(15.0)$ & $110(13.0)$ \\
\hline Never married & $187(42.6)$ & $116(28.4)$ & $303(35.8)$ \\
\hline \multicolumn{4}{|l|}{ Religion of respondent } \\
\hline Christian & $372(84.5)$ & $398(97.3)$ & $770(90.7)$ \\
\hline Muslim/Other & $68(15.5)$ & II (2.7) & $79(9.3)$ \\
\hline \multicolumn{4}{|l|}{ Highest level of education } \\
\hline Primary incomplete or none & $127(28.9)$ & $54(13.2)$ & $|8|(2 \mid .3)$ \\
\hline Primary complete & $193(44.0)$ & $156(38.1)$ & $349(4 I .2)$ \\
\hline Secondary complete & $66(15.0)$ & $120(29.3)$ & $186(21.9)$ \\
\hline Secondary incomplete & $45(10.3)$ & $56(13.7)$ & $10 \mid(\mid 1.9)$ \\
\hline College/University & $8(1.8)$ & $23(5.6)$ & $31(3.7)$ \\
\hline \multicolumn{4}{|l|}{ Spouse's level of education } \\
\hline Primary incomplete or none & $36(17.7)$ & $16(6.9)$ & $52(12)$ \\
\hline Primary complete & $61(30.0)$ & $55(23.8)$ & $116(26.7)$ \\
\hline Secondary complete & $58(28.6)$ & $108(46.8)$ & $166(38.2)$ \\
\hline Secondary incomplete & $21(10.3)$ & $19(8.2)$ & $40(9.2)$ \\
\hline College/university & $2(1.0)$ & $17(7.4)$ & $19(4.4)$ \\
\hline Don't Know & $25(12.3)$ & $16(6.9)$ & $4 \mid(9.4)$ \\
\hline \multicolumn{4}{|l|}{ Current main source of livelihood } \\
\hline Business & $79(38.9)$ & $67(29)$ & $146(33.6)$ \\
\hline Casual & $58(28.6)$ & $48(20.8)$ & $106(24.4)$ \\
\hline Salaried & $8(3.9)$ & $40(17.3)$ & $48(1 \mathrm{I} . \mathrm{I})$ \\
\hline Unemployed & $58(28.6)$ & $76(32.9)$ & $134(30.9)$ \\
\hline
\end{tabular}

Utilization of public and private health facilities was assessed using information obtained from women and caregivers of children. Women provided information on sources of family planning and delivery care while caregivers provided information on sources of care for child illnesses. A total of 37 I women (44\% of those interviewed) reported having ever used family planning, $606(71 \%)$ had ever been pregnant, and 536 ( $88 \%$ of those who had ever been pregnant) had given birth and provided information on the place of delivery. A total of 468 (47\%) children had been ill in the two weeks preceding the survey and caregivers of 255 (55\% of those who had been ill) reported that they sought treatment for the illnesses.
Among women who had ever used family planning (last time they had used), 47\% obtained the method from a private facility while $33 \%$ obtained it from a public facility (Table 3). There were, however, statistically significant variations in the sources of family planning by slum setting. In particular, the proportion of women who obtained family planning services from public health facilities was significantly higher in Korogocho than Viwandani (40\% and 26\% respectively; $p=0.005$ ). Further analysis showed that there were no significant variations in sources of family planning by age, religion, education and type of employment (not shown). 
Table 3: Public versus private health facility utilization for family planning, delivery and child treatment among slum residents

\begin{tabular}{lllllll}
\hline & \multicolumn{2}{l}{ Korogocho } & \multicolumn{2}{l}{ Viwandani } & \multicolumn{2}{l}{ Total } \\
\cline { 2 - 6 } & $\mathrm{n}$ & $\%$ & $\mathrm{n}$ & $\%$ & $\mathrm{n}$ & $\%$ \\
\cline { 2 - 6 } Source Family Planning $(\mathrm{n}=37 \mathrm{I})$ & & & & & & \\
$\quad$ Public & 69 & 39.9 & 52 & 26.3 & 121 & 32.6 \\
$\quad$ Private & 82 & 47.4 & 94 & 47.5 & 176 & 47.4 \\
$\quad$ Other source & 22 & 12.7 & 52 & 26.3 & 74 & 20.0 \\
Place of delivery $(\mathrm{n}=536)$ & & & & & & \\
$\quad$ Public & 79 & 27.0 & 82 & 33.7 & 161 & 30.0 \\
$\quad$ Private & 158 & 53.9 & 118 & 48.6 & 276 & 51.5 \\
$\quad$ Other source & 56 & 19.1 & 43 & 17.7 & 99 & 18.5 \\
Place sought child treatment $(\mathrm{n}=255)$ & & & & & & \\
$\quad$ Public & 47 & 32.2 & 35 & 32.1 & 82 & 32.2 \\
$\quad$ Private & 68 & 46.6 & 13 & 11.9 & 81 & 31.8 \\
$\quad$ Other source & 31 & 21.2 & 61 & 56.0 & 92 & 36.1 \\
\hline
\end{tabular}

Women who had given birth were asked about the place of delivery for the last birth. The majority $(51.5 \%)$ delivered in a private health facility with only $30 \%$ delivering in a public facility (Table 3 ). A higher proportion of women from Viwandani (34\%) than Korogocho $(27 \%)$ delivered in a public facility although the difference was not statistically significant. Similarly, the proportions of women that delivered in public health facilities were higher among those with no formal education, those not in salaried employment, and those divorced or widowed although the differences by these characteristics were not statistically significant (not shown).

Over $60 \%$ of children who were reported to be ill, the treatment was sought from private facilities

with the proportion being higher in Korogocho $(47.0 \%)$ than in Viwandani (I2\%), Table 3. Generally, children from Korogocho (16\%) and those whose mothers did not have any formal education (18\%) tended to seek care from multiple sources (both private and public).

Caregivers whose children were ill in the two weeks preceding the survey and sought care were asked about their perceptions of the quality of care received. The majority $(73 \%)$ perceived the quality of care received as good or very good with a slightly higher proportion of those who sought care from private than public facilities reporting such perception (Figure I).

Figure I: Perceived Quality of Care for Child health Services by facility ownership

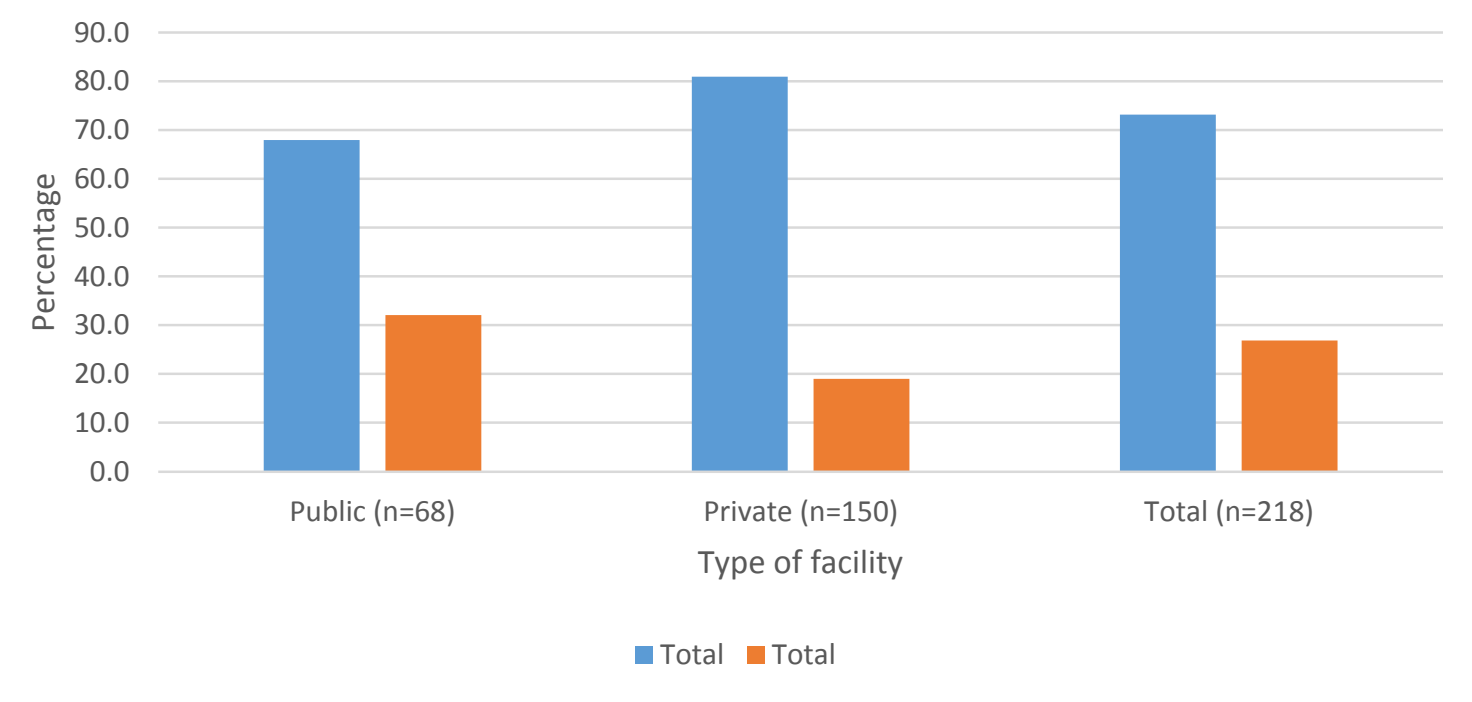


Results from qualitative analysis

Why private?

Accessibility

Timely access to vital health services is important to the improvement of health outcomes and the reduction of avoidable mortality. The main reason to account for user preference for private health facilities for maternity services was access. This access was noted in terms of service times, for the most part private facilities being open for longer hours than public health facilities, as illustrated in the quote below;

'Private is good since you can receive services at all times and the [public] you may not have money to go to [government hospital] or [public health centre] since they are not operational 24 hours. But the private will attend to you at any time, then the money will be paid later'- Younger women with children, Viwandani.

The other aspect of access is availability of health facilities. As noted in the survey, more women in Korogocho delivered from a private facility compared to those in Viwandani (Table 2). This is because there is only one public health facility in this slum.

'Private is good since it operates all the time, the [public] ones close at night. [Public] is cheap but has no drugs, in the private you are given drugs at that time. The private is good, they act swiftly and are close to us' -Older women with children, Korogocho.

\section{Quality of services and attitudes of clinicians}

The other important reason highlighted for preference for private health facilities was the quality of services provided. Quality of services was reflected in the time spent at the facility before services are received, availability of drugs and in the attitudes of the clinicians. In both slums, respondents reported that private facilities provide services faster because they have fewer clients and their clinicians are more courteous than those in public health facilities. These views are reflected in the quotes below.

I prefer private because as much as public hospitals might be having all the equipment they do not have the knowhow of using them; and they ignore people because they know at the end of the month their salary will be paid; but as for private hospitals they make you feel welcome'-Older women without children, Viwandani

'Personally, I prefer private hospitals because they are not abusive and they have to talk to you nicely because they know your money is what has brought you there. But with government whether he treats you or not they will still be paid. I have the experience and those who go to [public health centre] also know. There used to be a doctor there, who was bad and if you were late, let us say five minutes late, and the numbers are being given out, you would be welcomed with abuses. Those are the reasons that make me dislike them and if it were not for the funds [lack of money], I would not step in a government facility' -Younger women with children, Viwandani

\section{Demerits of Private Cost}

Although, private health facilities in the two communities are appreciated for their accessibility, the cost to clients for the same services is a major bone of contention with users. The discussions revealed that users felt that the services were expensive, and that clinicians valued money more than offering a service; as expressed in the quote below.

I would like to add that during delivery in the private hospital if a mother does not have the deposit they can't be allowed; there was a time that we delivered one on the way since she had not been allowed to get in.'-CHVs, Korogocho

\section{Inadequately trained clinicians}

In addition to cost, private health facilities are disliked because they, unlike public health facilities, quite often lack adequately trained clinicians to attend to clients' concerns. The respondents spoke of experiences were they felt that the clinicians were involved in games of guess work. Even in instances where they are unable to manage a condition, they hold onto clients unnecessarily without referring them on time or treat them without a proper diagnosis. This ultimately has financial and health implications as they would have to go elsewhere for treatment, quite often to public facilities or, in the worst case scenario, die without proper medication. The quote below illustrates this:

'... I prefer [public] facilities because in the private there are some doctors who do not have the experience; maybe I have pneumonia and I am treated for typhoid. So I like [public] since they do tests on the child and in case they need to be referred they are referred to the necessary facility. Like I had a child who I took to private and up to date he is disabled since they did not know what the problem was. But when we went to city council that is where they realized what his problem was so for me I prefer the government facility'-Older women with children Viwandani.

\section{Why public? \\ Affordability \\ Because public health services are either free or largely subsidised, some residents of these slums prefer to access services at public facilities.}


This was the main reason expressed by respondents for why public facilities were preferred;

'I love city council [public facility] because when it is my clinic day, I cannot miss my clinic because I didn't have the money but with private you have to pay before you are served. That means I will have to miss my clinic because I don't have the money. The baby will also be treated when it is sick and it is not a must that I have to have money in order to get those services. I just know that I will get assistance when I go there for whatever service I want be it family planning or sickness. Those are the reasons why I prefer [public] hospitals'-Older women with children Korogocho

\section{Expertise of clinicians}

Public health facilities are appreciated because they have a wide range of services and experts to provide the same, which is not usually the case in private health facilities, particularly those at the lower levels, as expressed below;

'For me I prefer the [public] ones because when you go to private and you have a headache they rush to injecting you yet they do not know why the headache is there; but in the public hospitals they take tests to know what your problem actually is before treating you. Like there is a time I went to the private hospital and was given an injection that almost killed me so when I went to the public hospital after they took the tests they were looking at the drugs I had been given and were calling each other to come and see what I had been given'.- CHVs, Korogocho.

'What I can say is that one should go to the hospital whether government or private; but as much as the government hospitals have got delays and congestions, they are the best because they offer better services; even if they might give you a prescription they are the best because they have professionals'-Younger women with children, Viwandani.

\section{Demerits of public}

\section{Long queues and lack of supplies}

Participants reported that public health facilities more often than not have many clients waiting for services yet they have few health workers to deal with the work load. The problem is compounded by frequent drug stock-outs which force patients to obtain their prescriptions from elsewhere:

'Also I do not know what is happening in the government hospitals because when you go there even to get a tetanus jab you have to wait for the injection to be brought from [private]. There is no fridge and so you have to wait for the person coming and at times you are sent back home and told to come back the following day yet you have been injured'.-CHVs, Korogocho.

'There are so many patients at the public hospitals that they really don't care at all. If you go to this hospital here like [private], they are very good with their services and you will be served very quickly. You cannot compare with [public] because with [public] you can stay even one week before you are attended to'.-Older women without children,Viwandani.

\section{Poor attitudes of clinicians}

Although public health facilities are appreciated for the expertise of their clinicians and the range of services available, the FGD participants expressed their displeasure with the negative attitudes in form of rudeness and arrogance, that many clinicians working in these facilities express towards clients.

'I would like to add that what my colleague has just mentioned is what makes most women don't like [public] maternities because the nurses there are very arrogant and they are always insulting patients. So this mother keeps saying; that day I paid my money just for a woman to go and insult me. Let me die in the house if that is what is going to happen. Therefore, [public] hospitals are scary because of the character of the nurses there; Hey, why are you screaming here, was I there with you?'-Younger Women with children-Korogocho.

Amidst these differences it is evident that both sectors have room for improvement; words reiterated from the FGD participants;

'So we are saying that both are good but they need to improve on the things that they do not have like in the city council the waiting time is what needs to improve; initially they had attitudes but were taken for training and now they have improved. But also the private have attitude like I will give an example. There is a child who was knocked down by a motorbike and he was taken to hospital but the person who took him did not have money, so in the hospital they asked for money but he said he wanted to leave the motorbike they told him that he has to also leave the key, so he called me and I went there personally and the boy was treated and we were discharged but the issue of taking the key is not right so [the research institution] should tell the staff what is right and what is not right since I know they want to improve the services there'.-CHVs Korogocho.

\section{Discussion}

This paper examined the source of care for essential maternal and child health services in urban slums of Nairobi as well as the perceptions of women and community health volunteers regarding the source and quality of care. Findings show that women utilise 
private health facilities more than public ones for delivery and family planning while for treatment of child illnesses they utilise public health facilities more than private ones. It has been previously reported that women in this setting use private health facilities for delivery care as these facilities are the majority (8). Our results support this earlier finding.

Regarding preferences for specific outlets, participants viewed private facilities as being easily accessible and providing services of good quality although their service fees were considered high and their staff having inadequate skills. On the other hand, public facilities are preferred for the affordable cost and the expertise of the clinicians and scorned for the long queues, frequent drug stock-outs and poor attitudes of the clinicians. These findings are consistent with those from other settings (3, 10-14). One review showed that private health facilities were less efficient, medically ineffective and less accountable than public facilities yet they scored better on timeliness and hospitality while public facilities were affected by shortages of skilled health care workers, drugs and equipment (3).

Although the findings of this paper show that private facilities were considered to offer better quality services than public outlets, findings from elsewhere indicate that the public sector can also offer better quality services than the private sector (27). In addition, other studies show that private facilities can be motivated to provide better quality services than the public sector since they do not depend on public subsidy and therefore require service fees to finance their operations (28).

The merits and demerits of public and private health service providers suggest that the two sectors complement each other thereby providing opportunities for harnessing the potential of publicprivate partnerships for promoting maternal and child health in informal settlements. Public-private partnerships in health care are an opportunity for the government and private providers to deal with the growing demand for care in a world of finite and dwindling public finances. Each sector has a role to play. In particular, whereas the government provides the policy framework to guide the structure, direction, regulations and trainings for health service delivery, the private sector provides capital, technology and expertise. In that way, both sectors contribute to advancing universal health coverage. As such, investments that support synergies between the two sectors are critical. However, a key question is what a successful partnership entails. Various models have been suggested for various settings based on experiences. Each country needs to define its partnership model based on its needs. For instance, a model is being tested in two slums of
Nairobi to assess the impact of interventions aimed at strengthening public-private partnerships on maternal, newborn, and child health outcomes (29). It is anticipated that the interventions will contribute to the body of knowledge on models of publicprivate partnerships for health service delivery for under-served populations in Kenya and other subSaharan African countries.

\section{Strengths and Limitations}

The focus group discussions were conducted in Kiswahili and later translated into English. Some degree of meaning is always lost during translation with potential impact on the study's validity. In addition, recall bias might have affected the responses in the survey. In spite of the limitations, the findings of this paper highlight the potential for both public and private sectors to complement each other in health service delivery for under-served populations.

\section{Conclusion}

Although women in Nairobi's informal settlements mostly seek health care services from private facilities, public health facilities are valued for their cost and the skills of the health providers. As such, given the roles that the two sectors play in health care provision in this and setting, there is need to support better public-private relationships in which the positive aspects of each sector are utilised and thus improve service delivery given that each sector has its merits and demerits.

\section{Authors' contributions}

PB managed the literature searches, analysed the qualitative data and drafted the manuscript. EK contributed to the literature searches. PB \& EK participated in the data collection exercise. TE \& AKZ analysed the survey data. AKZ, RE \& CK contributed to the study protocol upon which the study is based and contributed to writing the manuscript. All the authors read, reviewed, and approved of the final manuscript.

\section{Interests \\ None declared}

\section{Acknowledgements}

PAMANECH is funded by Comic Relief UK. The funder was not involved in the decision to develop and publish this manuscript. We acknowledge Jane Osindo and Nicholas Ngomi's contributions during the data collection phase and Djesika Amendah for the French version of the abstract. We are also grateful to the core funding to APHRC by SIDA and the Hewlett Foundation. 


\section{References}

World Bank. World Development Report 2004: Making Services Work for Poor People. Washington, D.C: World Bank., 2004.

WHO. Health Systems in Africa: community perception and perspectives. The report of a multi-country study. Geneva: : World Health Organization (WHO), 2012.

Basu S, Andrews J, Kishore S, Panjabi R, Stuckler D. Comparative performance of private and public healthcare systems in low- and middle-income countries: a systematic review. PLoS medicine. 20I2;9(6): el00I 244.

Basu S, Andrews, J., Kishore, S., Panjabi, R., \& Stuckler, D. Comparative Performance of Private and Public Healthcare Systems in Low- and Middle-Income Countries: A Systematic Review Plos Medicine. 2012.

Berman P, Laura R. The role of private providers in maternal and child health and family planning services in developing countries. Health policy and planning. 1996; I ( 2): | 42-55.

Saksena P, Xu K, Elovainio R, Perrot J. Utilization and expenditure at public and private facilities in 39 low-income countries. Tropical Medicine \& International Health. 20I 2; I 7(I):23-35.

Ekirapa A, Mgomella GS, Kyobutungi C. Civil society organizations: Capacity to address the needs of the urban poor in Nairobi. Journal of public health policy. 20 I 2;33(4):404-22.

Bazant ES, Koenig MA. Women's satisfaction with delivery care in Nairobi's informal settlements. International journal for quality in health care : journal of the International Society for Quality in Health Care / ISQua. 2009;2I (2):79-86.

Herrera CA, Rada G, Kuhn-Barrientos L, Barrios X. Does Ownership Matter? An Overview of Systematic Reviews of the Performance of Private For-Profit, Private Not-For-Profit and Public Healthcare Providers. 2014.

Brugha R, Zwi A. Improving the Quality of Private Sector Delivery of Public Health Services: Challenges and Strategies. Health policy and planning. 1998; | 3(2): I07-20.

Zwi $A B$, Brugha $R$, Smith E. Private health care in developing countries: If it is to work, it must start from what users need. BMJ: British Medical Journal. 200I;323(73II):463.

Sauerborn R. Low quality of care in low income countries: is the private sector the answer? International Journal for Quality in Health Care. 2014; I3(4):28I-2.

Amooti-Kaguna B, Nuwaha F. Factors influencing choice of delivery sites in Rakai district of Uganda. Social science \& medicine (1982). 2000;50(2):20313.
Fotso JC, Mukiira C. Perceived quality of and access to care among poor urban women in Kenya and their utilization of delivery care: harnessing the potential of private clinics? Health policy and planning. 20I 2;27(6):505-I5.

Fotso J-C, Ezeh A, Madise N, Ziraba A, Ogollah R. What does access to maternal care mean among the urban poor? Factors associated with use of appropriate maternal health services in the slum settlements of Nairobi, Kenya. Maternal and child health journal. 2009; I 3(I): I 30-7.

Rutebemberwa E, Pariyo G, Peterson S, Tomson G, Kallander K. Utilization of public or private health care providers by febrile children after user fee removal in Uganda. Malaria journal. 2009;8(I):45.

Konde-Lule J, Okuonzi, S., Matsiko, C., Mukanga, D., Onama, V. \& Gitta, S. The Potential of the Private sector to improve health outcomes in Uganda. 2006.

Ajayi IO, Browne EN, Garshong B, Bateganya F, Yusuf B, Agyei-Baffour $P$, et al. Feasibility and acceptability of artemisinin-based combination therapy for the home management of malaria in four African sites. Malaria Journal. 2008;7(I):6.

Patouillard E, Goodman CA, Hanson KG, Mills AJ. Can working with the private for-profit sector improve utilization of quality health services by the poor? A systematic review of the literature. International journal for equity in health. 2007;6(I): 17.

UN-HABITAT. State of the World's Cities 2008/2009: Harmonious Cities. Nairobi, Kenya: United Nations Human Settlements Programme (UN-HABITAT), 2008.

KNBS. Kenya Demographic and Health Survey 200809. Calverton, Maryland: KENYA NATIONAL BUREAU OF STATISTICS (KNBS) \& ICF MACRO, 2010.

Kyobutungi C, Ziraba AK, Ezeh A, Yé Y. The burden of disease profile of residents of Nairobi's slums: Results from a Demographic Surveillance System. Population health metrics. 2008;6(I): I.

Ziraba AK, Madise N, Mills S, Kyobutungi C, Ezeh A. Maternal mortality in the informal settlements of Nairobi city: what do we know. Reprod Health. 2009;6(6):4755-6.

Ziraba AK, Mills S, Madise N, Saliku T, Fotso J-C. The state of emergency obstetric care services in Nairobi informal settlements and environs: Results from a maternity health facility survey. BMC health services research. 2009;9(I):46.

APHRC. Population and Health Dynamics in Nairobi's Informal Settlements. Nairobi: African Population and Health Research Center (APHRC), 2014.

Graneheim UH, Lundman B. Qualitative content analysis in nursing research: concepts, procedures 
and measures to achieve trustworthiness. Nurse education today. 2004;24(2): 105- 12.

Camilleri D, O'Callaghan M. Comparing public and private hospital care service quality. International journal of health care quality assurance incorporating Leadership in health services. I998; I | (4-5): | 27-33.

Andaleeb SS. Public and private hospitals in Bangladesh: service quality and predictors of hospital choice. Health policy and planning. 2000; I5(I):95-102.

Bakibinga P, Ettarh R, Ziraba AK, Kyobutungi C, Kamande E, Ngomi N, et al. The effect of enhanced public-private partnerships on Maternal, Newborn and child Health Services and outcomes in Nairobi-Kenya: the PAMANECH quasiexperimental research protocol. BMJ open. 20I4;4(I0):e006608. 